This is an author produced version of a paper published in European Journal of Pharmacology. This paper has been peer-reviewed but does not include the final publisher proof-corrections or journal pagination.

Citation for the published paper:

Wackenfors, Angelica and Vikman, Petter and Nilsson, Elisabeth and Edvinsson, Lars and Malmsjo, Malin

"Angiotensin II-induced vasodilatation in cerebral arteries is mediated by endothelium-derived hyperpolarising factor."

Eur J Pharmacol. 2006 Feb 15;531(1-3):259-63

http://dx.doi.org/10.1016/j.ejphar.2005.11.064

Access to the published version may require journal subscription.

Published with permission from: Elsevier. 


\section{Angiotensin II-induced vasodilatation in cerebral arteries is mediated by endothelium-derived hyperpolarising factor}

*Angelica Wackenfors, Petter Vikman, Elisabeth Nilsson, Lars Edvinsson and Malin Malmsjö

Division of Experimental Vascular Research, Department of Clinical Science, Lund University Hospital, Lund, Sweden

\footnotetext{
* Author for correspondence:

Angelica Wackenfors, PhD

Division of Experimental Vascular Research

BMC A13

Lund University Hospital

SE-221 84 Lund

Sweden

Phone: +46 462220617

Fax: +46 462220616

angelica.wackenfors@med.lu.se
} 


\section{Abstract}

The angiotensin II-induced vasodilatation was evaluated in rat middle cerebral artery, especially regarding endothelium-derived hyperpolarising factor (EDHF), by use of a pressurised arteriograph. The angiotensin II dilatation was partly antagonised by inhibitors of nitric oxide synthase and cyclo-oxygenase. The remaining dilatation was inhibited by the potassium channel blockers, charybdotoxin and apamin, providing direct evidence that angiotensin II induces EDHF-mediated dilatation in cerebral arteries. The angiotensin II dilatation was blocked by the angiotensin $\mathrm{AT}_{1}$ and $\mathrm{AT}_{2}$ receptor blockers candesartan and $\mathrm{PD}$ 123319. Both angiotensin $\mathrm{AT}_{1}$ and $\mathrm{AT}_{2}$ receptors were detected on the endothelium by immunohistochemistry.

Keywords: Angiotensin II, cerebral arteries, vasodilatation, endothelium-derived hyperpolarising factor 


\section{Introduction}

Angiotensin II controls vascular tone by activating angiotensin type $1\left(\mathrm{AT}_{1}\right)$ and type $2\left(\mathrm{AT}_{2}\right)$ receptors (Chiu et al., 1989). Angiotensin $\mathrm{AT}_{1}$ receptors are believed to be mainly located on smooth muscle cells and to induce vasoconstriction (Touyz and Schiffrin, 2000), while angiotensin $\mathrm{AT}_{2}$ receptors mediate endothelium-dependent vasodilatation (Carey et al., 2000). In the peripheral circulation, blood vessel tone is primarily controlled by vasoconstrictors. Conversely, the intracranial vascular tone is predominantly influenced by vasodilatory mediators (Toda and Okamura, 1998).

Endothelium-dependent dilatation has mainly been characterised by the use of strong vasodilators such as acetylcholine, bradykinin and substance P. Nitric oxide and prostaglandins are well-characterised vasodilatory mediators, while the existence of endothelium-derived hyperpolarising factor (EDHF) in cerebral blood vessels was unknown until 1995 (Petersson et al., 1995). It is now believed that EDHF is one of the most important regulators of cerebrovascular tone (Kitazono et al., 1995; Petersson et al., 1997; Schildmeyer and Bryan, 2002).

Angiotensin II-induced vasodilatation has been shown to be mediated by nitric oxide and prostaglandins (Henrion et al., 2001). Involvement of EDHF was observed in a recent study on the peripheral rat vasculature (Soares de Moura et al., 2004). The dilatory mechanisms of angiotensin II have not yet been fully explored in the cerebral circulation and the role of EDHF remains to be elucidated. The present study was designed to examine the angiotensin II-induced vasodilatation in cerebral arteries, especially regarding EDHF. By applying the drugs luminally in a pressurised arteriograph, the dilatory angiotensin II receptors on the 
endothelium could be examined without the interference of vasocontractile angiotensin II receptors on smooth muscle cells. 


\section{Materials and Methods}

\subsection{In vitro pharmacology}

Middle cerebral artery segments (1-2 mm in length) from male Sprague-Dawley rats (250300 g) were mounted in a pressurised arteriograph (Living System, Burlington, VT, USA) containing a bicarbonate-based physiological salt solution $\left(37^{\circ} \mathrm{C}\right)$. Micropipettes were inserted into both ends of the segment and secured in place with nylon ties. The transmural pressure was maintained at $85 \mathrm{mmHg}$ and the luminal perfusion rate was $100 \mu \mathrm{l} / \mathrm{min}$. The blood vessel was monitored using a microscope coupled to an Axis digital camera (Axis, Lund, Sweden), and the program Mary ${ }^{\circledR}$ (Nihil KB, Lund, Sweden) was used to save images and measure the blood vessel diameter every second. The pressurised arteriograph consists of a luminal and an abluminal compartment. Pharmacological agents added to the luminal perfusate selectively stimulate the endothelial cells, while agents added to the abluminal bath stimulate the smooth muscle cells. The arteries were allowed to stabilise and were used for further experiments providing that a spontaneous tone of $>20 \%$ of the initial diameter was developed within $1 \mathrm{~h}$. ATP-induced dilation reaching $>10 \%$ of the resting diameter indicated the presence of a functional endothelium. The experiments were approved by the Ethics Committee for Animal Research in Lund, Sweden, and performed in accordance with the European Community guidelines for the use of experimental animals. For method details see Hansen-Schwartz et al., 2003.

Candesartan (1 nM) and S-(+)-1-[(4-(dimethylamino)-3-methylphenyl)methyl]-5(diphenylacetyl)-4,5,6,7-tetrahydro-1H-imidazo[4,5-c]pyridine-6-carboxylic acid ditrifluoroacetate (PD 123319, $0.1 \mu \mathrm{M}$ ) were added $1 \mathrm{~h}$ before the experiment was started. $N^{\mathrm{G}}$-nitro-L-arginine (L-NOARG, $\left.0.1 \mathrm{mM}\right)$ and indomethacin $(10 \mu \mathrm{M})$ were used to inhibit nitric oxide synthase and cyclo-oxygenase respectively, while a combination of the potassium 
channel blockers charybdotoxin (50 nM) and apamin $(1 \mu \mathrm{M})$ was used to inhibit EDHF. These antagonists were added luminally, 30 min prior to the experiment. The blood vessels were precontracted with $1 \mu \mathrm{M}$ 5-hydroxytryptamine (5-HT) and angiotensin II was added to the luminal perfusate in increasing concentrations ( $0.1 \mathrm{pM}-0.1 \mathrm{mM})$. The artery segments were perfused with angiotensin II until a maximum vasodilatation for each concentration was reached, approximately two minutes. For the vasoconstriction experiments, angiotensin II was added to the abluminal perfusate. The concentration-response experiment was performed once for each artery.

\subsection{Immunohistochemistry}

The blood vessel segments were frozen in isopentane and then kept at $-80^{\circ} \mathrm{C}$ until sectioning. The segments were sectioned into $10 \mu \mathrm{m}$ thick slices and subsequently fixed in ice cold acetone. The slices of the arteries were incubated with the primary antibodies, rabbit antihuman angiotensin $\mathrm{AT}_{1}$ receptor and rabbit antihuman angiotensin $\mathrm{AT}_{2}$ receptor. Donkeyantirabbit Cy ${ }^{\mathrm{TM}} 3$ was used as the secondary antibody. The antibodies were detected using a confocal microscope (Zeiss, Thornwood, NY, USA).

\subsection{Drugs}

Angiotensin II, apamin, ATP, charybdotoxin, 5-HT, indomethacin and L-NOARG were obtained from Sigma Co, St Louis, MO, USA. Candesartan and PD 123319 were generous gifts from Peter Morsing, AstraZeneca, Sweden. The drugs were dissolved in 0.9\% saline apart from angiotensin II, which was dissolved in $0.1 \%$ bovine serum albumin. The primary antibodies, rabbit antihuman angiotensin $\mathrm{AT}_{1}$ receptor and rabbit antihuman angiotensin $\mathrm{AT}_{2}$ receptor, were obtained from Santa Cruz Biotechnology, Santa Cruz, CA, USA. The secondary antibody, donkeyantirabbit $\mathrm{Cy}^{\mathrm{TM}} 3$, was obtained from Jackson ImmunoResearch, Cambridgeshire, UK. All antibodies were diluted 1:100 in PBS with 10\% fetal calf serum. 


\subsection{Calculations and statistics}

$\mathrm{E}_{\max }$ denotes the maximal angiotensin II dilatation as a percent of the 5-HT precontraction. $\mathrm{pEC}_{50}$ denotes the negative logarithm of the angiotensin II concentration that elicits $50 \%$ dilatation. The angiotensin II control experiment was repeated twelve times while the other experiments were repeated five times in different rats. Statistical significance was defined as $P<0.05$, using Student's t-test when comparing two groups, and analysis of variance with Dunnett's correction test when comparing more than two groups. Values are presented as mean values \pm S.E.M. 


\section{Results}

The mean baseline diameter of the middle cerebral arteries examined was $195 \pm 13 \mu \mathrm{m}$ after initial pressurisation, and $136 \pm 6 \mu \mathrm{m}$ after development of spontaneous tone. Luminally applied ATP $(10 \mu \mathrm{M})$ produced relaxation to $156 \pm 9 \mu \mathrm{m}$, indicating a functional endothelium. The precontraction induced by abluminal application of $1 \mu \mathrm{M} 5$-HT amounted to $122 \pm 4 \mu \mathrm{m}$.

Abluminal application of angiotensin II induced vasoconstriction ( $E_{\max }=15 \pm 1 \%$ of the initial diameter, $\mathrm{pEC}_{50}=8.0 \pm 0.1$ ). Luminal application of angiotensin II induced vasodilatation $\left(E_{\max }=39 \pm 11 \%\right.$ of $\left.5-H T, \mathrm{pEC}_{50}=8.6 \pm 0.8\right)$. When the dilatory experiment was performed after luminal administration of L-NOARG $(0.1 \mathrm{mM})$ and indomethacin $(10 \mu \mathrm{M})$ to eliminate any contribution from nitric oxide and prostaglandins, respectively, the angiotensin II-induced dilatation was partially antagonised $\left(\mathrm{E}_{\max }=16 \pm 4 \%\right.$ of 5 -HT, Fig. $\left.1 \mathrm{~A}\right)$. However, angiotensin II failed to induce dilatation after luminal administration of the potassium channel inhibitors charybdotoxin (50 nM) and apamin $(1 \mu \mathrm{M})$ in combination with indomethacin and L-NOARG ( $E_{\max }=4 \pm 2 \%$ of 5-HT, Fig. 1A), indicating the presence of EDHF-mediated dilatation.

Luminal application of the angiotensin $\mathrm{AT}_{1}$ receptor blocker candesartan $(1 \mathrm{nM})$ and the angiotensin $\mathrm{AT}_{2}$ receptor blocker PD 123319 (0.1 $\left.\mu \mathrm{M}\right)$ inhibited angiotensin II-induced dilatation ( $E_{\max }=9 \pm 1 \%$ and $25 \pm 9 \%$, respectively, Fig. 1B). A combination of PD 123319 and candesartan administered luminally completely abolished the response (Fig. 1B). Application of PD 123319 and candesartan abluminally did not affect the dilatory response to angiotensin II (Fig. 1C). Both angiotensin $\mathrm{AT}_{1}$ and $\mathrm{AT}_{2}$ receptors were detected by immunohistochemistry in the endothelial and smooth muscle cell layer of the rat middle cerebral artery (Fig. 2). 


\section{Discussion}

EDHF is an endothelium-dependent dilatory mediator that has been suggested to play a major role in the regulation of blood flow in the cerebral circulation (Petersson et al., 1995; Petersson et al., 1997; Schildmeyer and Bryan, 2002). The present study was designed to investigate the angiotensin II dilatory effects in cerebral arteries in detail, especially with regard to EDHF, since this pathway has not yet been fully elucidated in the cerebrovasculature.

Angiotensin II is a strong vasoconstrictor peptide. Recent experiments, using a wire myograph, provide evidence that angiotensin II contracts the rat middle cerebral artery (Stenman and Edvinsson, 2004). Conversely, the present results indicate that angiotensin II is a potent vasodilator of the rat middle cerebral artery when studied in a pressurised arteriograph. The reason for the discrepancy is probably due to the methods used. In a study by Zwart et al., 1998 it was made clear that the vasodilatory effects of angiotensin II can not be studied by use of a wire myograph, where both the endothelium and the smooth muscle cells are exposed to angiotensin II. In the present study, the endothelium function in middle cerebral arteries was examined in a sensitive pressurised arteriograph. In the cerebral circulation, the blood-brain barrier separates the endothelium from the smooth muscle cells. By applying the pharmacological substances luminally or abluminally, the different cell functions can be studied separately by use of a pressurised arteriograph. The dilatory effect of luminally applied angiotensin II is therefore endothelium specific. The endothelium specificity is supported by the lack of inhibitory effect of the abluminally applied angiotensin II receptor antagonists PD 123319 and candesartan at angiotensin II-induced dilatation. When angiotensin II was administered abluminally to stimulate smooth muscle cells, vasoconstriction was induced. 
Previous studies have suggested that angiotensin II-induced vasodilatation is mediated by the release of nitric oxide and prostaglandins (Henrion et al., 2001). This was confirmed by the present results as the inhibition of nitric oxide synthase by L-NOARG and of cyclo-oxygenase by indomethacin partially reduced the angiotensin II dilatation. In the presence of L-NOARG and indomethacin, EDHF is the sole mediator of vasodilatation (Chataigneau et al., 1998). Although the criterion defining EDHF varies, consensus has been reached that EDHF induces endothelium-dependent dilatation and hyperpolarisation of smooth muscle cells that can not be blocked by nitric oxide synthase or cyclo-oxygenase antagonists, whereas it can be inhibited by a combination of the potassium channel blockers charybdotoxin and apamin (Edwards and Weston, 2001). When applying the potassium channel inhibitors, charybdotoxin and apamin, in combination with L-NOARG and indomethacin in the present experiments, the angiotensin II response was completely abolished, indicating the involvement of EDHF.

The intracranial vascular tone is predominantly influenced by vasodilators over vasoconstrictors (Toda and Okamura, 1998). By using vasodilators, e.g. acetylcholine, substance P and ATP, it has been shown that EDHF is one of the most important regulators of cerebrovascular tone (Petersson et al., 1997; Schildmeyer and Bryan, 2002). Very little is known about the identity of EDHF in cerebral vessels, and the response appears to be different from that in peripheral vessels (Dong et al., 2000; Schildmeyer and Bryan, 2002). It is therefore imperative that EDHF be studied in cerebral vessels independently of peripheral vessels. Examining the dilatory effect of strong vasoconstrictors is difficult, and detailed studies on the mediators involved in angiotensin II dilatation, including EDHF, are rare. The present study is the first to demonstrate that EDHF is involved in angiotensin II dilatation in cerebral blood vessels. By using a cannulated, pressurised rat mesenteric vascular bed it was 
recently shown that EDHF contributes to the angiotensin II-induced vasodilatation (Soares de Moura et al., 2004), which supports our results.

Angiotensin II controls vascular tone via the angiotensin $\mathrm{AT}_{1}$ and $\mathrm{AT}_{2}$ receptors. It is believed that angiotensin $\mathrm{AT}_{1}$ receptors on smooth muscle cells induce vasoconstriction (Touyz and Schiffrin, 2000), while angiotensin $\mathrm{AT}_{2}$ receptors stimulate endothelium-dependent vasodilatation (Carey et al., 2000). The angiotensin II-induced vasodilatation in the present study was shown to depend on both angiotensin $\mathrm{AT}_{1}$ and $\mathrm{AT}_{2}$ receptors on the endothelium, since both candesartan and PD 123319 had inhibitory effects. Furthermore, both angiotensin $\mathrm{AT}_{1}$ and $\mathrm{AT}_{2}$ receptors were visualised by immunohistochemistry in the endothelial layer of the rat middle cerebral artery. These findings argue against the assumption that vasodilatation is a specific function of one of these receptor subtypes (Haberl, 1994). The angiotensin $\mathrm{AT}_{1}$ receptor subtypes couple to $G_{q}$-mediated responses and not to $G_{i}$-mediated responses such as inhibition of adenylate cyclase (Tian et al., 1996). This suggests that the dilator response in the present study is induced by angiotensin $\mathrm{AT}_{1}$ receptors on the endothelium and not on smooth muscle cells.

Angiotensin $\mathrm{AT}_{1}$ receptors have been further subdivided into angiotensin $\mathrm{AT}_{1 \mathrm{~A}}$ and $\mathrm{AT}_{1 \mathrm{~B}}$ subtypes in some rodents, including rats (Iwai and Inagami, 1992). In contrast to the angiotensin $\mathrm{AT}_{1 \mathrm{~A}}$ subtype, the angiotensin $\mathrm{AT}_{1 \mathrm{~B}}$ receptor can be inhibited by a high concentration (> $0.5 \mu \mathrm{M}$ ) of PD 123319 (Guimaraes and Pinheiro, 2005). In the present setting, a low concentration of PD $123319(0.1 \mu \mathrm{M})$ was used, only affecting the angiotensin $\mathrm{AT}_{2}$ receptors. There is evidence that angiotensin $\mathrm{AT}_{1 \mathrm{~B}}$ receptors acts indirectly through the facilitation of the exocytic release of noradrenaline from sympathetically innervated tissues, while angiotensin $\mathrm{AT}_{1 \mathrm{~A}}$ receptors acts directly on vascular cells (Guimaraes and Pinheiro, 2005). In the present study, the angiotensin $\mathrm{AT}_{1}$ receptor effect is most probably mediated by 
the angiotensin $\mathrm{AT}_{1 \mathrm{~A}}$ receptor subtype, since angiotensin II was administered on the luminal side of the artery to stimulate vascular tissue where mainly angiotensin $\mathrm{AT}_{1 \mathrm{~A}}$ receptors are present (Guimaraes and Pinheiro, 2005). Although, a subdivision into different angiotensin $\mathrm{AT}_{1}$ receptor subtypes can not be done from the present results.

In conclusion, EDHF has been suggested to play a major role in the regulation of cerebrovascular tone. In the present study, it is shown for the first time that angiotensin II dilatation is mediated by EDHF in cerebral arteries. The dilatory effects of angiotensin II act via both angiotensin $\mathrm{AT}_{1}$ and $\mathrm{AT}_{2}$ receptors on the endothelium. 


\section{Acknowledgements}

This study was supported by the Åke-Wieberg Foundation, the Magn. Bergvall Foundation, the Swedish Medical Association, the Royal Physiographic Society in Lund, the Swedish Medical Research Council, the Crafoord Foundation, the Swedish Heart-Lung Foundation, the Swedish Government Grant for Clinical Research and the Swedish Hypertension Society. 


\section{References}

Carey, R.M., Wang, Z.Q., Siragy, H.M., 2000. Update: role of the angiotensin type-2 (AT(2)) receptor in blood pressure regulation. Curr. Hypertens. Rep. 2, 198-201.

Chataigneau, T., Feletou, M., Duhault, J., Vanhoutte, P.M., 1998. Epoxyeicosatrienoic acids, potassium channel blockers and endothelium-dependent hyperpolarization in the guinea-pig carotid artery. Br. J. Pharmacol. 123, 574-580.

Chiu, A.T., Herblin, W.F., McCall, D.E., Ardecky, R.J., Carini, D.J., Duncia, J.V., Pease, L.J., Wong, P.C., Wexler, R.R., Johnson, A.L., et al., 1989. Identification of angiotensin II receptor subtypes. Biochem. Biophys. Res. Commun. 165, 196203.

Dong, H., Jiang, Y., Cole, W.C., Triggle, C.R., 2000. Comparison of the pharmacological properties of EDHF-mediated vasorelaxation in guinea-pig cerebral and mesenteric resistance vessels. Br. J. Pharmacol. 130, 1983-1991.

Edwards, G., Weston, A.H., 2001. EDHF -- are there gaps in the pathway? J. Physiol. 531, 299.

Guimaraes, S., Pinheiro, H., 2005. Functional evidence that in the cardiovascular system AT1 angiotensin II receptors are AT1B prejunctionally and AT1A postjunctionally. Cardiovasc. Res. 67, 208-215.

Haberl, R.L., 1994. Role of angiotensin receptor subtypes in the response of rabbit brain arterioles to angiotensin. Stroke. 25, 1476-1479; discussion 1480.

Hansen-Schwartz, J., Lovland Hoel, N., Nilsson, E., Tfelt-Hansen, P., Edvinsson, L., 2003. Endothelium-dependent relaxant responses to selective 5-HT(1B/1D) receptor agonists in the isolated middle cerebral artery of the rat. J. Vasc. Res. 40, 561566.

Henrion, D., Kubis, N., Levy, B.I., 2001. Physiological and pathophysiological functions of the AT(2) subtype receptor of angiotensin II: from large arteries to the microcirculation. Hypertension. 38, 1150-1157.

Iwai, N., Inagami, T., 1992. Identification of two subtypes in the rat type I angiotensin II receptor. FEBS. Lett. 298, 257-260.

Kitazono, T., Faraci, F.M., Taguchi, H., Heistad, D.D., 1995. Role of potassium channels in cerebral blood vessels. Stroke. 26, 1713-1723.

Petersson, J., Zygmunt, P.M., Brandt, L., Hogestatt, E.D., 1995. Substance P-induced relaxation and hyperpolarization in human cerebral arteries. Br. J. Pharmacol. 115, 889-894.

Petersson, J., Zygmunt, P.M., Hogestatt, E.D., 1997. Characterization of the potassium channels involved in EDHF-mediated relaxation in cerebral arteries. Br. J. Pharmacol. 120, 1344-1350.

Schildmeyer, L.A., Bryan, R.M., Jr., 2002. Effect of NO on EDHF response in rat middle cerebral arteries. Am. J. Physiol. Heart. Circ. Physiol. 282, H734-738.

Soares de Moura, R., Resende, A.C., Emiliano, A.F., Tano, T., Mendes-Ribeiro, A.C., Correia, M.L., de Carvalho, L.C., 2004. The role of bradykinin, AT2 and angiotensin 1-7 receptors in the EDRF-dependent vasodilator effect of angiotensin II on the isolated mesenteric vascular bed of the rat. $\mathrm{Br}$. J. Pharmacol. 141, 860-866.

Stenman, E., Edvinsson, L., 2004. Cerebral ischemia enhances vascular angiotensin AT1 receptor-mediated contraction in rats. Stroke. 35, 970-974.

Tian, Y., Baukal, A.J., Sandberg, K., Bernstein, K.E., Balla, T., Catt, K.J., 1996. Properties of AT1a and AT1b angiotensin receptors expressed in adrenocortical Y-1 cells. Am. J. Physiol. 270, E831-839. 
Toda, N., Okamura, T., 1998. Cerebral vasodilators. Jpn. J. Pharmacol. 76, 349-367.

Touyz, R.M., Schiffrin, E.L., 2000. Signal transduction mechanisms mediating the physiological and pathophysiological actions of angiotensin II in vascular smooth muscle cells. Pharmacol. Rev. 52, 639-672.

Zwart, A.S., Davis, E.A., Widdop, R.E., 1998. Modulation of AT1 receptor-mediated contraction of rat uterine artery by AT2 receptors. Br. J. Pharmacol. 125, 14291436. 


\section{Figure legends}

Fig.1: Vasodilatory responses to angiotensin II, added luminally (L) in the absence (control) and presence of $\mathbf{( A )}$ the nitric oxide inhibitor L-NOARG (0.1 mM), the cyclo-oxygenase inhibitor indomethacin $(10 \mu \mathrm{M})$ and the potassium channel blockers charybdotoxin $(50 \mathrm{nM})$ and apamin $(1 \mu \mathrm{M})$, added luminally, (B) the angiotensin $\mathrm{AT}_{1}$ receptor antagonist candesartan (1 $\mathrm{nM})$ and the angiotensin $\mathrm{AT}_{2}$ receptor antagonist PD $123319(0.1 \mu \mathrm{M})$, added luminally, and (C) candesartan (1 nM) and PD 123319 (0.1 $\mu \mathrm{M})$, added abluminally (AL).

Concentration-response curves for angiotensin II were constructed after precontraction with $1 \mu \mathrm{M}$ 5-HT, added abluminally. Values are shown as means \pm S.E.M.

Fig. 2: Immunohistochemistry slides showing (A) angiotensin $A_{1}$ receptors and (B) angiotensin $\mathrm{AT}_{2}$ receptors, both on the smooth muscle cells (SMC) as well as on the endothelial cells (EC) of the artery. (C) An antibody negative slide. Sizebar $=20 \mu \mathrm{m}, \mathrm{L}=$ luminal side. 
Fig. 1
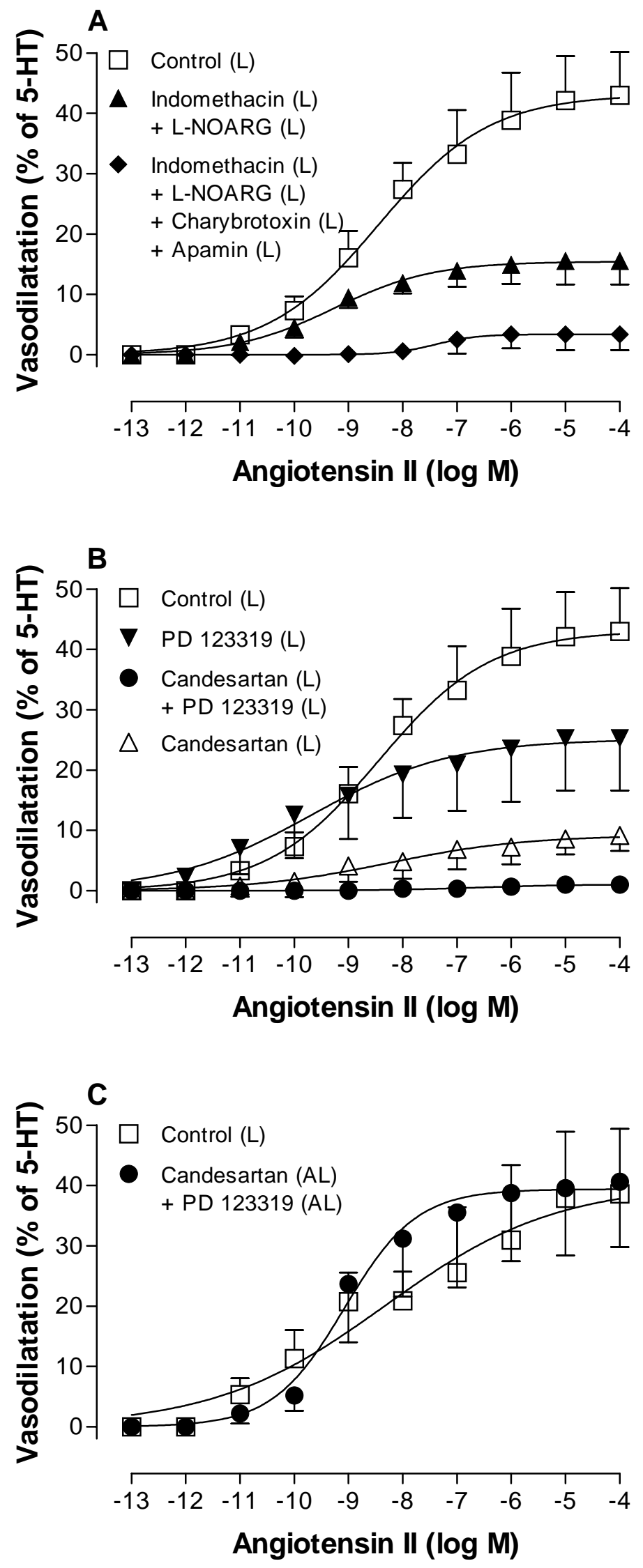
Fig. 2

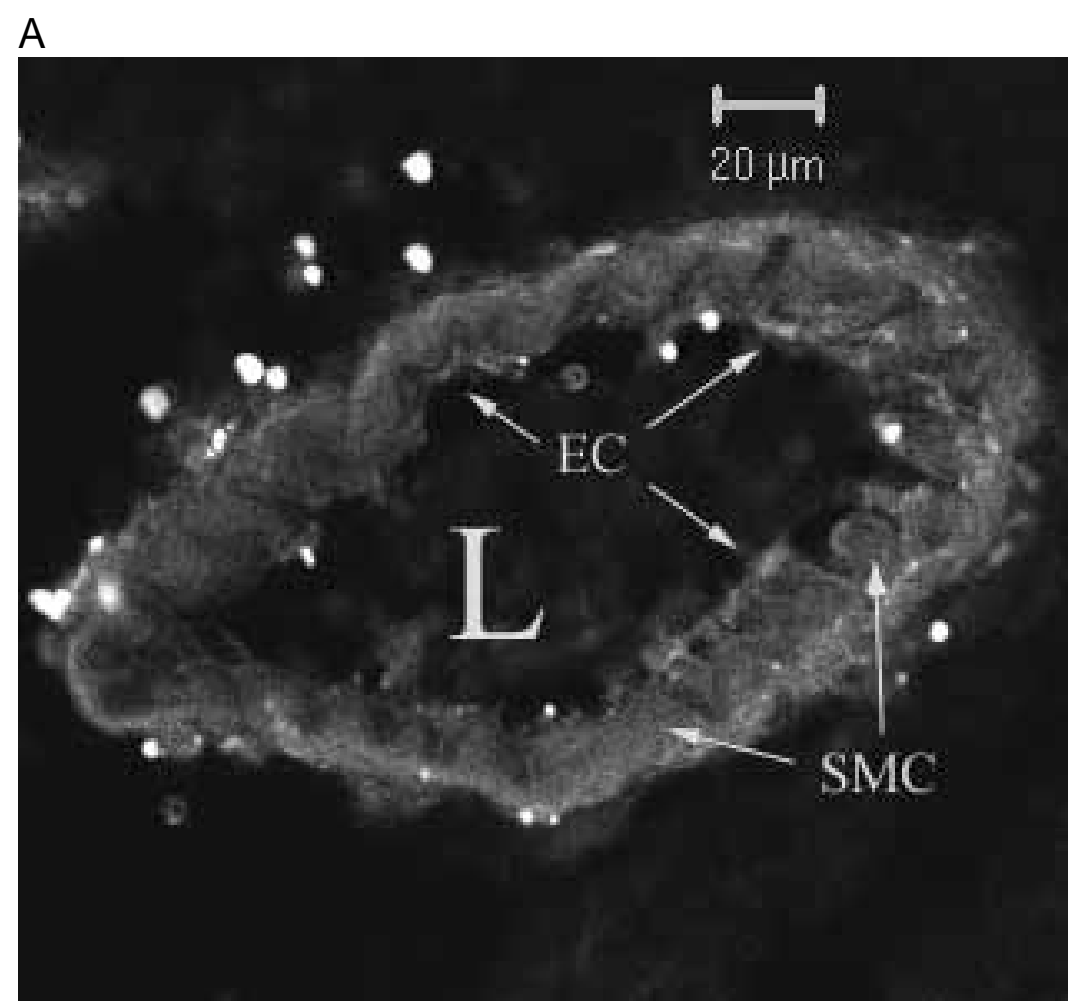

B

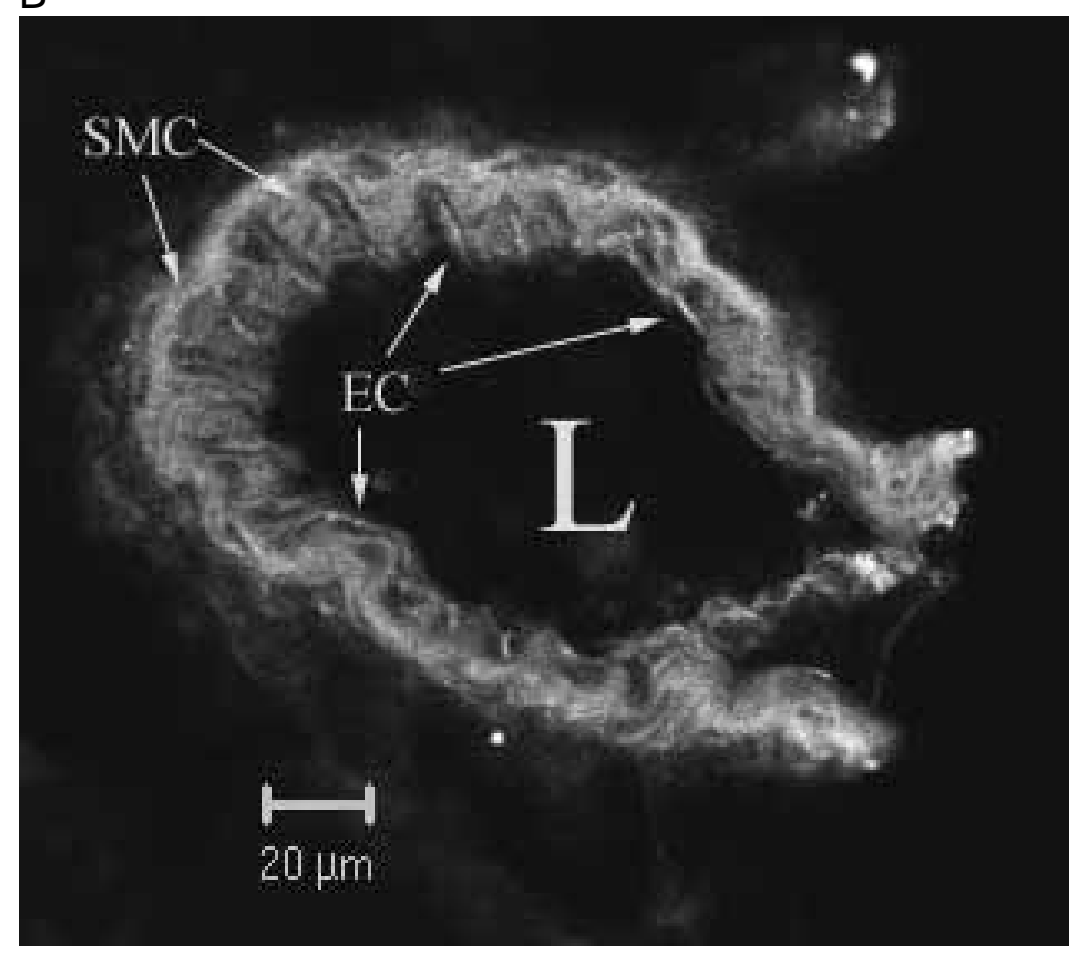


C

$\longmapsto$

$20 \mu \mathrm{m}$

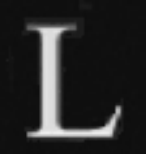

